\title{
Prevalence and risk factors of nocturnal enuresis among children ages $5-12$ years in Xi'an, China: a cross-sectional study
}

Hui-Mei Huang ${ }^{2,3,1+}$, Jing Wei ${ }^{1+}$, Shristi Sharma', Ying Bao ${ }^{3}$, Fei Li $i^{4}$, Jian-Wen Song ${ }^{5}$, Hai-Bin Wu ${ }^{6}$, Hong-Li Sun', Zhi-Juan Li ${ }^{3}$, Huan-Nan Liu', Qian Wu ${ }^{1 *}$ (D) and Hong-Li Jiang ${ }^{2^{*}}$

\begin{abstract}
Background: Nocturnal enuresis (NE) has a negative impact on children's health and imposes a long-term burden on families. With economic development and cultural improvements, parents and medical professionals pay more attention to NE. The aim of this study was to investigate the prevalence and risk factors of NE among children ages 5-12 years in Xi'an, China.

Methods: A stratified cluster sampling method was used to conduct a cross-sectional study of NE in 10 kindergartens and 20 primary schools in Xi'an. We used univariate analysis to compare the prevalences of characteristics such as gender, duration of disposable diaper (DD) use, toilet training onset time, daily living habits, academic performance, and family history of NE. Logistic regression analysis was used to calculate odds ratio and to determine risk factors of NE.

Results: The study included 6568 children ages 5-12 years, of which 262 (3.99\%) had NE. The prevalence rates of NE decreased with age, with the highest prevalence at age 5 (9.09\% for boys; $6.03 \%$ for girls). However, the prevalence increased with duration of DD use. Children experienced more NE if they never accepted toilet training (7.83\%) or if they drank sugary beverages during the day (5.36\%). Sleep disorders, sweets intake, drinking low amounts of plain water during the day, and family history of NE, were statistically associated with NE.

Conclusion: NE was closely associated with a family history of NE, being male, long-term use of DD, delayed toilet training, drinking sugary beverages and/or consuming little plain water, and sleep disorders. A supportive parental attitude towards NE and timely medical treatment can improve the quality of life of enuretic children.
\end{abstract}

Keywords: Nocturnal enuresis, Children, Prevalence, Risk factors

\footnotetext{
* Correspondence: epiwuqian@163.com; j92106@sina.com

Jing Wei is the co-first author.

${ }^{\dagger}$ Hui-Mei Huang and Jing Wei contributed equally to this work.

'Department of Epidemiology and Biostatistics, School of Public Heath, Xi'an

Jiaotong University, No.76 West Yanta Road, Xi'an 710061, Shaanxi, China

${ }^{2}$ Department of Renal Dialysis, The First Affiliated Hospital of Xi'an Jiaotong

University, No.277 West Yanta Road, Xi'an 710061, Shaanxi, China

Full list of author information is available at the end of the article
}

(c) The Author(s). 2020 Open Access This article is licensed under a Creative Commons Attribution 4.0 International License, which permits use, sharing, adaptation, distribution and reproduction in any medium or format, as long as you give appropriate credit to the original author(s) and the source, provide a link to the Creative Commons licence, and indicate if changes were made. The images or other third party material in this article are included in the article's Creative Commons licence, unless indicated otherwise in a credit line to the material. If material is not included in the article's Creative Commons licence and your intended use is not permitted by statutory regulation or exceeds the permitted use, you will need to obtain permission directly from the copyright holder. To view a copy of this licence, visit http://creativecommons.org/licenses/by/4.0/ The Creative Commons Public Domain Dedication waiver (http://creativecommons.org/publicdomain/zero/1.0/) applies to the data made available in this article, unless otherwise stated in a credit line to the data. 


\section{Background}

Childhood nocturnal enuresis (NE) refers to the symptoms of intermittent urinary incontinence during sleep, at a minimum age of 5 years, with a minimum duration of three months, and a minimum of one episode per month [1]. The pathogenesis of NE is complex and multifactorial. Contributing elements include family history of NE, changes in antidiuretic hormone secretion rhythm, sleep disorders, retarded bladder maturity, immature nerve development, psychology, and environment [2-4].

In Egypt, Hamed et al. found the prevalences of NE in rural and urban areas were 17.5 and $18.4 \%$ [2]. In Turkey, the overall occurrence of NE was 7.5-16.2\% [3, 5, 6], and, in Iran, the prevalence was $8-18.7 \%$ [4, 7]. Furthermore, Ramírez-Backhaus et al. found that the prevalence of NE in Spanish schoolage children was 7.8\% [8]. In China, NE prevalence was found to vary by region, ranging from 4.07 to $10.3 \%[9,10]$, and NE occurred more frequently with boys $[3,11]$.

The risk factors for NE include long-term use of disposable diaper (DD) [10], being male, difficulty in awakening at night [11], mental stress, poverty [12], and family environment [13]. With the use of $\mathrm{DD}$, toilet training may be delayed. In western countries, parents initiate toilet training depending on a child's physical and psychological development, usually between the age of 21 and 36 months [14]. Because of the advent of DD, more and more parents start toilet training after their children's second birthday. Some children have never been trained. However, in traditional Chinese culture, parents usually begin toilet training before children's first birthday. In rural areas, some children even receive toilet training within 6 months of birth. A study has confirmed that infants who use DD and receive toilet training within the age of 12 months have better control over urination than those who delay toilet training [15]. Although NE does not cause physical problems, and 10-15\% of enuretic children recover spontaneously, parents and medical practitioners cannot ignore the negative influence of $\mathrm{NE}$ on a child's social, emotional, and psychological development $[16,17]$. Also, NE brings greater economic burden and mental pressure to families. However, most parents have a casual attitude towards this condition, and lack awareness of medical treatment, which ultimately causes delay in treatment [18]. Fortunately, economic development and cultural improvement are promoting increased attention to NE among parents and medical professionals. Economic development may make parents more attentive towards child's health, and their awareness of NE makes them consider NE to be a developmental problem for their child. Moreover, cultural awareness has led to greater acceptance of NE as a problem, which allows many children and/or parents to open about the problem.

To date, there are no large-scale epidemiological surveys of NE in Xi'an. There is a small-scale survey conducted in
2005 that showed a $5.2 \%(84 / 1626)$ prevalence of NE among school-age children [19]. Thus, we sought to investigate the prevalence of NE in children ages 5-12 years in Xi'an and assess potential risk factors of NE, to provide baseline data for prevention and treatment.

\section{Methods \\ Study participants}

From December 2018 to January 2019, we conducted a cross-sectional survey of NE among children ages 5-12 years in five regions throughout Xi'an. Ten kindergartens and 20 primary schools were selected by stratified cluster sampling. NE was diagnosed according to ICCS-2016 [1].

\section{Survey method}

The investigators in each school received standardized training. They obtained informed consent from a parent or guardian on behalf of all participants. Parents received questionnaires including informed consent at the parent-teacher conference, using the "Questionnaire Star" software. They completed the questionnaires in the class as a unit.

\section{Content of questionnaire}

To design the questionnaire, we referred to research of $\mathrm{Ma}$ and Tang $[19,20]$. The questionnaire included an introduction that explained the importance of the study.

The questionnaire had five parts: general items, life behavior characteristics, quality of life, family history of NE, and parental attitude towards NE. "The Questionnaire for the Assessment of Children's General Quality of Life" was compiled by referring to similar studies from other countries, taking into account current conditions in China [19]. All answers were divided according to increasing frequency of occurrence. Referring to the WHOQOL-BREF scale [21], 25 items were ranked into four dimensions: physiology, psychology, social relations, and environment. All items had 1-5 points; items 3, 7, 9, 10, 11, 15, 18, 19, 21 and 23 were scored backwards. Children were divided into two age groups (5-6 and 7$12)$, when calculating quality of life scores. The higher the average score of each dimension, the better the quality of life.

\section{Statistical methods}

The mean, standard deviation (SD), median, quartile range and frequency were used to describe the data. Two Independent Sample $\mathrm{T}$ test and the Mann-Whitney $\mathrm{U}$ test were used for analysis of quantitative data; otherwise, a Chi-squared test and Chi-squared test for trend were used to compare the distribution of categorical variables. Logistic regression analysis was used for multivariate analysis. A $P$-value $<0.05$ was considered to be statistically significant. The Statistical Package for Social 
Sciences (SPSS; version 13.0, IBM, Armonk, NY, USA) was used for all statistical tests.

\section{Results}

We distributed 6590 questionnaires; participants returned 6568 (99.67\%) valid questionnaires, of which 3409 (51.90\%) were from boys.

Table 1 lists the general characteristics of the study children. The average ages $( \pm \mathrm{SD})$ of children with and without NE were $7.21( \pm 1.99)$ and $8.05( \pm 2.08)$ years $(t=$ - 6.413, $P<0.001$ ). Otherwise, between NE and non-NE groups, there were no significant differences in the distributions of mother's age at delivery and parental education level.

The frequency of NE among children ages 5-12 was $3.99 \%$ (262/6568), with a higher prevalence among boys $\left(4.96 \%\right.$ vs $2.94 \%, X^{2}=17.356, P<0.001$, Table 1$)$. The prevalence of NE in 5-year-old children was higher than the prevalence at older ages $(9.09 \%$ for boys; $6.03 \%$ for girls). With increasing age, the prevalence rates of NE for boys and girls both showed downward trends (Fig. 1 and Supplementary Table 1, Additional File 1).

The prevalences of NE in five regions were as follows: urban area, 4.24\%; eastern suburb, $3.00 \%$; western suburb, 2.31\%; southern suburb, $4.77 \%$; northern suburb, $3.60 \%$. The differences between regions were statistically significant $\left(\chi^{2}=12.013, P=0.017\right)$.

The prevalence of NE among children increased with duration of DD use. Statistically, the children who never accepted toilet training (7.83\%) and those who drank sugary beverages during the day (5.36\%) experienced more NE compared with others. Children who drank plain water and ate fruits before bed $(4.42 \%)$, or had sleep disorders $(5.98 \%)$, or who awakened with difficulty from sleep $(4.43 \%)$ had more NE than children without these behaviors and symptoms. The prevalence of NE in children with poor academic performance and family history of NE was 13.49 and $18.04 \%$, respectively (Table 2 ).

Logistic regression analysis showed that being female, older and exhibiting good academic performance appeared to be protective factors for NE. Long-term use of DD (more than one year), delayed toilet training, drinking sugary beverages, consuming low amounts of plain water $(<500 \mathrm{ml})$ during the day, falling asleep late, sleep disorders, and family history of NE correlated positively with occurrence of NE (Table 3).

Compared with children without NE, the quality of life scores of enuretic children in physiology and social relations were lower in two age groups $(P<0.05)$. As for the psychological field, there was a significant difference in quality of life scores between NE and non-NE groups, only in children ages $7-12$ (36 vs $38, P<0.001$; Supplementary Table 2, Additional File 1).

\section{Discussion}

Nocturnal enuresis (NE) is a common childhood condition. Its pathogenesis is complex and associated with many factors [20]. In 2005, the prevalence of NE among all primary school students in China was $4.6 \%$. For selected cities, the prevalence of NE was 7.4\% in Wuhan, 3.3\% in Shanghai, and 5.2\% in Xi'an [19]. However, compared to the findings of the 2005 study in Xi'an, our sample's prevalence of NE was lower, 3.99\%. This lower prevalence might have been due to improvements in income, parental occupation, parental education level, and living habits [9].

We found that the prevalence of NE was higher in boys than girls. The highest frequency was $9.09 \%$ for boys and $6.03 \%$ for girls at age 5 . The incidence of NE is known to decrease gradually with age, and our results also showed the same downward trend. We also found that age was a protective factor for NE, consistent with previous research $[2,22]$. Age may relate to decreasing rates of NE because a child's central nervous system develops with increasing age, and the neural pathways that control urination can better regulate urination activities, manage the storage and discharge of urine at night, and reduce the occurrence of bed-wetting [23].

We also found that being female and having good academic performance were protective factors of NE, findings that agreed with another study [11]. Genetic factor plays a decisive role in NE [3], and the poor control of nervous system over the bladder at night may be more heritable in boys than in girls [24], so boys are more likely to wet their beds than girls. In addition, bedwetting has a negative effect on the body and mind [16] and it results in poor sleep quality in children with NE; this effect may cause enuretic children to be selfconscious and unable to concentrate on their studies, leading to poor academic performance.

NE has been closely associated with DD use, family income, and parental education level [12, 25, 26]. However, in our study, the difference in parental education levels was not statistically significant. In addition, we found that the prevalence of NE varied with regions, with the highest in the southern suburb followed by the urban area. This regional variation might exist because of rapid development of the economy in the southern suburb and urban area. We also found that with the widespread use of DD, younger children had used it much longer than the older (Supplementary Table 3, Additional File 1). Due to increases in income, parents may prolong the use of DD and delay toilet training, thus promoting the occurrence of NE [9]. Joinson et al. [27] suggested that delayed toilet training (after 24 months) was likely to induce persistent urine accidents during the daytime. But Hodges et al. found that children with early (before 24 months) or late (after 36 
Table 1 General characteristics of children ages 5-12 years

\begin{tabular}{|c|c|c|c|c|c|c|c|}
\hline Factors & & Total number & $\mathrm{NE}$ & non-NE & Prevalence(\%) & $x^{2}$ & $P$ \\
\hline Age & & - & $7.21 \pm 1.99$ & $8.05 \pm 2.08$ & - & -6.413 & $<0.001^{*}$ \\
\hline \multirow[t]{2}{*}{ Gender } & Male & 3409 & 169 & 3240 & 4.96 & 17.356 & $<0.001$ \\
\hline & Female & 3159 & 93 & 3066 & 2.94 & & \\
\hline \multirow[t]{6}{*}{ Educational level of father } & Primary school & 194 & 14 & 180 & 7.22 & 0.405 & $0.525^{* *}$ \\
\hline & Junior high school & 1761 & 65 & 1696 & 3.69 & & \\
\hline & High school & 1454 & 58 & 1396 & 3.99 & & \\
\hline & Junior college & 1538 & 62 & 1476 & 4.03 & & \\
\hline & Bachelor degree & 1348 & 55 & 1293 & 4.08 & & \\
\hline & Postgraduate and above & 273 & 8 & 265 & 2.93 & & \\
\hline \multirow[t]{6}{*}{ Educational level of mother } & Primary school & 238 & 16 & 222 & 6.72 & 0.085 & $0.770^{* *}$ \\
\hline & Junior high school & 1826 & 66 & 1760 & 3.61 & & \\
\hline & High school & 1463 & 58 & 1405 & 3.96 & & \\
\hline & Junior college & 1621 & 64 & 1557 & 3.95 & & \\
\hline & Bachelor degree & 1254 & 53 & 1201 & 4.23 & & \\
\hline & Postgraduate and above & 166 & 5 & 161 & 3.01 & & \\
\hline \multirow[t]{4}{*}{ Mother's age at delivery } & $<20$ years old & 63 & 5 & 58 & 7.94 & 0.732 & $0.392^{* *}$ \\
\hline & 20-29 years old & 4957 & 186 & 4771 & 3.75 & & \\
\hline & 30-39years old & 1509 & 70 & 1439 & 4.64 & & \\
\hline & $\geq 40$ years old & 39 & 1 & 38 & 2.56 & & \\
\hline
\end{tabular}

Note: $\mathrm{NE}=$ nocturnal enuresis. Age is mean $\pm \mathrm{SD}$. ${ }^{*} P$ value for Two Independent Sample T test, ${ }^{* *} P$ value for Chi-squared test for trend, and other $P$ value for Chi-squared test

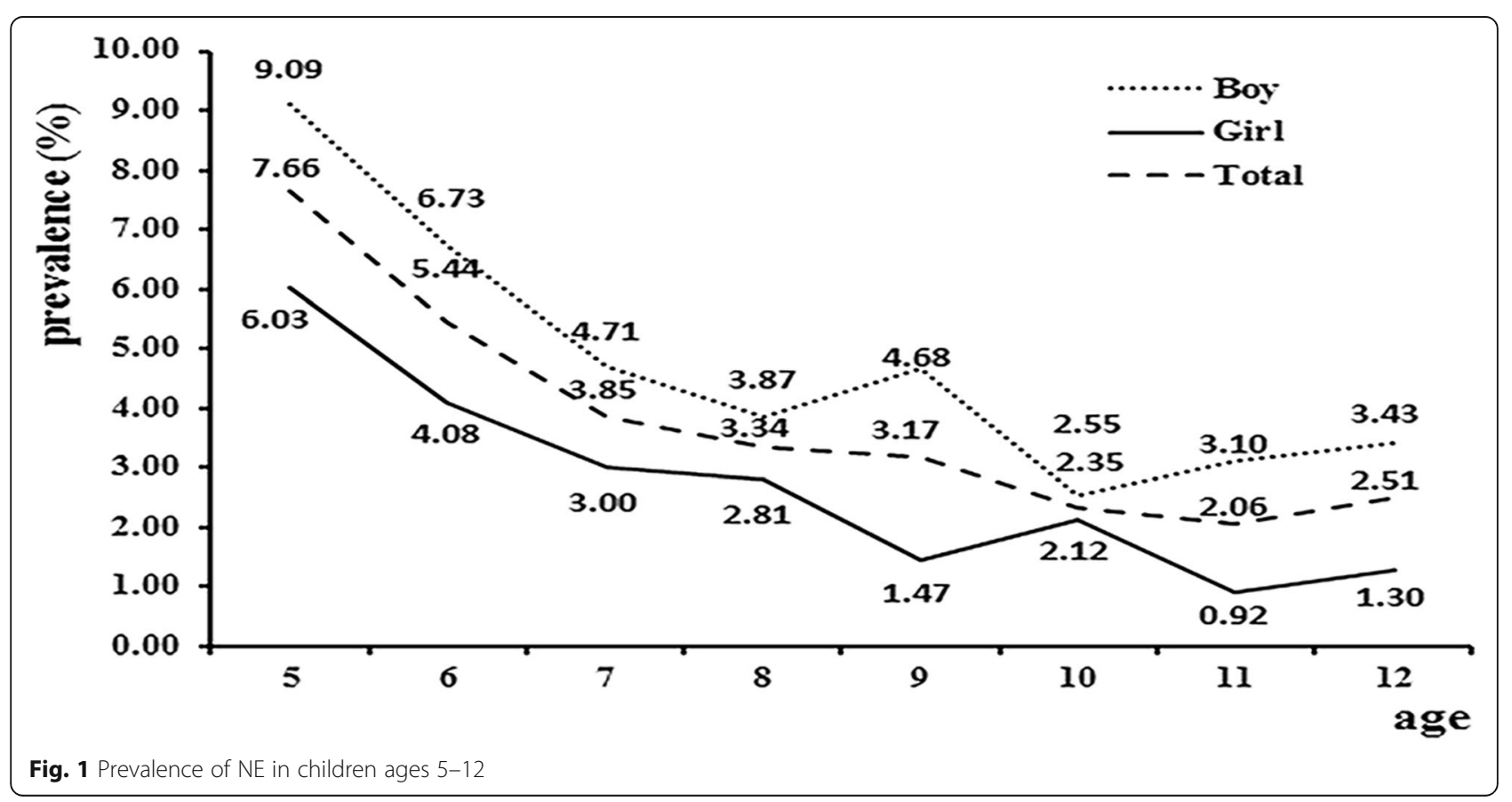


Table 2 Univariate analysis of associated factors of NE among children ages 5-12 years

\begin{tabular}{|c|c|c|c|c|c|c|c|}
\hline Factors & & $\begin{array}{l}\text { Total } \\
\text { number }\end{array}$ & $\mathrm{NE}$ & $\begin{array}{l}\text { non- } \\
\text { NE }\end{array}$ & Prevalence(\%) & $x^{2}$ & $P$ \\
\hline \multirow[t]{2}{*}{ Delivery mode } & Natural labor & 3576 & 125 & 3451 & 3.50 & 4.992 & 0.025 \\
\hline & Caesarean birth & 2992 & 137 & 2855 & 4.58 & & \\
\hline \multirow[t]{6}{*}{ Duration of using DD } & Never use & 994 & 19 & 975 & 1.91 & 131.360 & $<0.001^{* *}$ \\
\hline & 0-1 year & 2532 & 59 & 2473 & 2.33 & & \\
\hline & $>1$ but $\leq 2$ years & 2492 & 122 & 2370 & 4.90 & & \\
\hline & $>2$ but $\leq 3$ years & 454 & 32 & 422 & 7.05 & & \\
\hline & $>3$ but $\leq 4$ years & 67 & 16 & 51 & 23.88 & & \\
\hline & $>4$ years & 29 & 14 & 15 & 48.28 & & \\
\hline \multirow[t]{5}{*}{ Toilet training onset time } & $<6$ months of age & 2368 & 71 & 2297 & 3.00 & 20.940 & $<0.001^{* *}$ \\
\hline & $6-12$ months of age & 2555 & 107 & 2448 & 4.19 & & \\
\hline & 13-18 months of age & 998 & 37 & 961 & 3.71 & & \\
\hline & $>18$ months of age & 149 & 8 & 141 & 5.37 & & \\
\hline & never training & 498 & 39 & 459 & 7.83 & & \\
\hline \multirow[t]{4}{*}{ Living habits during the day } & Drinking sugary beverages & 971 & 52 & 919 & 5.36 & 16.304 & 0.001 \\
\hline & Eating sweets & 1645 & 74 & 1571 & 4.50 & & \\
\hline & $\begin{array}{l}\text { drinking low amounts of plain water }(< \\
500 \mathrm{ml})\end{array}$ & 1505 & 68 & 1437 & 4.52 & & \\
\hline & None of the above & 2447 & 68 & 2379 & 2.78 & & \\
\hline \multirow{2}{*}{$\begin{array}{l}\text { Drinking plain water and eating fruits } \\
\text { before bed }\end{array}$} & No & 2429 & 79 & 2350 & 3.25 & 5.462 & 0.019 \\
\hline & Yes & 4139 & 183 & 3956 & 4.42 & & \\
\hline \multirow[t]{3}{*}{ The time to fall asleep } & Before 21:00 & 1114 & 24 & 1090 & 2.15 & 14.757 & $<0.001^{* *}$ \\
\hline & 21:00-23:00 & 5354 & 230 & 5124 & 4.30 & & \\
\hline & After 23:00 & 100 & 8 & 92 & 8.00 & & \\
\hline \multirow[t]{2}{*}{ Awakening from sleep } & Easy & 2122 & 65 & 2057 & 3.06 & 7.017 & 0.008 \\
\hline & Difficult & 4446 & 197 & 4249 & 4.43 & & \\
\hline \multirow[t]{2}{*}{ Sleep disorders } & Yes & 1773 & 106 & 1667 & 5.98 & 25.100 & $<0.001$ \\
\hline & No & 4795 & 156 & 4639 & 3.25 & & \\
\hline \multirow[t]{3}{*}{ Playing games before bed } & No & 4384 & 161 & 4223 & 3.67 & 3.884 & $0.049^{* *}$ \\
\hline & Sometimes & 2103 & 96 & 2007 & 4.56 & & \\
\hline & Often & 81 & 5 & 76 & 6.17 & & \\
\hline \multirow[t]{3}{*}{ Academic performance } & Good & 4289 & 149 & 4140 & 3.47 & 17.053 & $<0.001^{* *}$ \\
\hline & General & 2153 & 96 & 2057 & 4.46 & & \\
\hline & Poor & 126 & 17 & 109 & 13.49 & & \\
\hline \multirow[t]{3}{*}{ Family history of NE } & No & 4939 & 77 & 4862 & 1.56 & 390.83 & $<0.001$ \\
\hline & Not sure & 1130 & 95 & 1035 & 8.41 & & \\
\hline & Yes & 499 & 90 & 409 & 18.04 & & \\
\hline
\end{tabular}

Note: $\mathrm{NE}=$ nocturnal enuresis; $\mathrm{DD}=$ disposable diaper. ${ }^{* *} P$ value for Chi-squared test for trend, and other $\mathrm{P}$ value for Chi-squared test

months) toilet training had more complaints of daytime wetness than children with normal training [28]. The difference in the age of toilet training may be due to individual differences of children and different childrearing concepts of parents in different cultures. Children who use DD at night may attain nighttime dryness later compared to those who do not use DD at night. Therefore, parents should be encouraged to watch for signs that their child wakes up in the night for urination or is staying dry during the night. These cues might indicate readiness for a trial without DD.

The occurrence of NE is also closely related to sleep disorders $[29,30]$. If they play games before bed, children with poor sleep quality could aggravate their fatigue and easily have difficulty waking from sleep [26, 31], in turn, inducing bed-wetting. 
Table 3 Logistic regression analysis of associated factors of NE in children ages 5-12 years

\begin{tabular}{|c|c|c|c|c|c|c|c|}
\hline Factors & & $B$ & SE & Wals & $P$ & OR & $95 \% \mathrm{Cl}$ \\
\hline \multirow[t]{2}{*}{ Gender } & Male & & & & & 1 (ref) & \\
\hline & Female & -0.444 & 0.145 & 9.416 & 0.002 & 0.641 & $0.483-0.852$ \\
\hline Age & - & -0.173 & 0.037 & 21.492 & $\begin{array}{l}< \\
0.001\end{array}$ & 0.841 & $0.782-0.905$ \\
\hline \multirow[t]{2}{*}{ Delivery mode } & Natural labor & & & & & 1 (ref) & \\
\hline & Caesarean birth & 0.222 & 0.137 & 2.629 & 0.105 & 1.248 & $0.955-1.632$ \\
\hline \multirow[t]{6}{*}{ Duration of using DD } & Never use & & & & & 1 (ref) & \\
\hline & 0-1 year & 0.121 & 0.278 & 0.188 & 0.665 & 1.128 & $0.654-1.947$ \\
\hline & $>1$ but $\leq 2$ years & 0.734 & 0.267 & 7.575 & 0.006 & 2.084 & $1.235-3.516$ \\
\hline & $>2$ but $\leq 3$ years & 0.856 & 0.319 & 7.208 & 0.007 & 2.354 & $1.260-4.399$ \\
\hline & $>3$ but $\leq 4$ years & 2.055 & 0.419 & 24.080 & $\begin{array}{l}< \\
0.001\end{array}$ & 7.806 & $\begin{array}{l}3.435- \\
17.737\end{array}$ \\
\hline & $>4$ years & 3.119 & 0.503 & 38.471 & $\begin{array}{l}< \\
0.001\end{array}$ & 22.624 & $\begin{array}{l}8.444- \\
60.620\end{array}$ \\
\hline \multirow[t]{5}{*}{ Toilet training onset time } & $<6$ months of age & & & & & 1 (ref) & \\
\hline & $6-12$ months of age & 0.257 & 0.167 & 2.369 & 0.124 & 1.293 & $0.932-1.795$ \\
\hline & 13-18 months of age & 0.011 & 0.222 & 0.003 & 0.959 & 1.011 & $0.655-1.562$ \\
\hline & $>18$ months of age & -0.048 & 0.418 & 0.013 & 0.909 & 0.953 & $0.420-2.164$ \\
\hline & Never training & 0.557 & 0.240 & 5.376 & 0.020 & 1.745 & $1.090-2.793$ \\
\hline \multirow{2}{*}{$\begin{array}{l}\text { Drinking plain water and eating fruits before } \\
\text { bed }\end{array}$} & No & & & & & 1 (ref) & \\
\hline & Yes & 0.110 & 0.150 & 0.536 & 0.464 & 1.116 & $0.832-1.496$ \\
\hline \multirow[t]{4}{*}{ Living habits during the day } & None of the following & & & & & 1 (ref) & \\
\hline & drinking sugary beverages & 0.604 & 0.212 & 8.112 & 0.004 & 1.830 & $1.207-2.773$ \\
\hline & Eating sweets & 0.308 & 0.187 & 2.705 & 0.100 & 1.361 & $0.943-1.965$ \\
\hline & $\begin{array}{l}\text { drinking low amounts of plain water }(<500 \\
\mathrm{ml})\end{array}$ & 0.526 & 0.191 & 7.536 & 0.006 & 1.692 & $1.162-2.462$ \\
\hline \multirow[t]{3}{*}{ The time to fall asleep } & Before 21:00 & & & & & 1 (ref) & \\
\hline & 21:00-23:00 & 0.457 & 0.232 & 3.886 & 0.049 & 1.579 & $1.003-2.486$ \\
\hline & After 23:00 & 0.604 & 0.479 & 1.595 & 0.207 & 1.830 & $0.716-4.677$ \\
\hline \multirow[t]{2}{*}{ Awakening from sleep } & Easy & & & & & 1 (ref) & \\
\hline & Difficult & -0.283 & 0.156 & 3.278 & 0.070 & 0.753 & $0.555-1.024$ \\
\hline \multirow[t]{2}{*}{ Sleep disorders } & No & & & & & 1 (ref) & \\
\hline & Yes & 0.291 & 0.141 & 4.235 & 0.040 & 1.338 & $1.014-1.764$ \\
\hline \multirow[t]{3}{*}{ Playing games before bed } & No & & & & & 1 (ref) & \\
\hline & Sometimes & -0.068 & 0.147 & 0.212 & 0.645 & 0.934 & $0.700-1.247$ \\
\hline & Often & -0.273 & 0.534 & 0.261 & 0.609 & 0.761 & $0.267-2.167$ \\
\hline \multirow[t]{3}{*}{ Academic performance } & Poor & & & & & 1 (ref) & \\
\hline & General & -1.033 & 0.328 & 9.937 & 0.002 & 0.356 & $0.187-0.677$ \\
\hline & Good & -1.276 & 0.326 & 15.346 & $\begin{array}{l}< \\
0.001\end{array}$ & 0.279 & $0.148-0.529$ \\
\hline \multirow[t]{3}{*}{ Family history of NE } & No & & & & & 1 (ref) & \\
\hline & Not sure & 1.549 & 0.164 & 89.245 & $\begin{array}{l}< \\
0.001\end{array}$ & 4.705 & $3.412-6.488$ \\
\hline & Yes & 2.458 & 0.172 & 204.34 & $\begin{array}{l}< \\
0.001\end{array}$ & 11.680 & $\begin{array}{l}8.336- \\
16.355\end{array}$ \\
\hline
\end{tabular}


In addition to heredity, daily living habits are associated with NE. We found that the occurrence of NE in children with a family history of NE was significantly higher than that in the general population. In addition, behavioral factors can also induce NE. If children drink much sugary beverages during the day, it may have diuretic effects and lead to bed-wetting at night.

Parents may not consider NE to be a problem that could be helped by a physician, thus, they ignore it. Of the 262 enuretic children in our study, only 78 sought medical care, and parents of 136 enuretic children blamed and scolded their children for bed-wetting (Supplementary Table 4, Additional File 1). Parents who do not seek medical treatment for their children usually resort to potentially harmful, non-medical measures to prevent bed-wetting, such as waking their children to urinate at night and limiting water and fruit intake before bed [32]. A study has confirmed that NE was closely associated with parental abuse and neglect, which severely damages children's psychological development and family life quality [33].

$\mathrm{NE}$ has a negative impact on children and families [17]. We found that children with NE scored lower in quality of life than children without NE in physiological health and social relations. This phenomenon may have occurred because enuretic children slept on damp beds and were liable to become unwell because of poor physical resistance, in turn promoting a poor quality of life [19]. We also found that NE appeared to have a great impact on psychology among older children (7-12 years old). Children with NE may be derided and disliked by classmates and have low self-esteem, which may affect their ability to communicate and hinder their progress in toilet training and their psychological development [34]. NE imposes a long-term burden on families, which may cause parents to have negative feelings about their child.

The limitations are that the results were possibly compromised by the potential retrospective recall biases, such as memory bias of the parents' report on the duration of using DD and age of toilet training onset. This study was performed in order to establish baseline data that would lead to more comprehensive studies on NE. The causes for NE may be multifactorial, and the medical community needs more prospective studies to verify its risk factors.

\section{Conclusion}

This study was the first large-scale cross-sectional survey of NE in children, ages 5-12, in Xi'an, China. The major strengths of the study are the large sample size and its epidemiological and representative design because the sample covered five regions throughout Xi'an, including urban and rural areas. The prevalence of NE was 3.99\%, lower than the frequency in 2005. Prevalence decreased with age and was higher in boys and in economically developed areas. NE was closely associated with a family history of NE, being male, long-term use of DD (more than one year), delayed toilet training, sugary beverage consumption, lack of plain water intake, and sleep disorders. Early toilet training, a helpful parental attitude towards NE, and concern for children's physical and mental health are likely to improve the quality of life for children who experience NE.

\section{Supplementary information}

Supplementary information accompanies this paper at https://doi.org/10. 1186/s12887-020-02202-W.

Additional file 1. Supplementary Table 1 Prevalence of NE in boys and girls ages 5-12. Supplementary Table 2 Quality of life scores of children in two age groups. Supplementary Table 3 Age of children in DD use groups. Supplementary Table 4 Parental attitude and behaviors towards enuretic children. Description of data: The four supplementary tables in Additional File 1 contain additional information that supports our findings in the main manuscript.

\section{Abbreviations}

NE: Nocturnal enuresis; DD: Disposable diaper; ref.: Reference; SD: Standard deviation; $\mathrm{Cl}$ : Confidence interval

\section{Acknowledgements}

The authors sincerely thank all the participants in this study and AiMi Academic Services for English language editing and review services.

\section{Authors' contributions}

$\mathrm{HMH}$ developed the project, collected data and revised the manuscript; JW analyzed data, wrote and revised the manuscript; SS revised the manuscript; YB developed the project; FL, JWS, HBW, HLS, ZJL and HLJ collected data; $\mathrm{HNL}$ analyzed data; QW developed the project and revised the manuscript. All authors read and approved the final manuscript.

\section{Funding}

This study was supported by the Program for Tackling Key Problems in Shaanxi Provincial Science and Technology (2016SF-288). The funding body played no role in the design of the study and the collection, analysis, and interpretation of data and in writing the manuscript.

\section{Availability of data and materials}

The datasets used and/or analyzed during the current study available from the corresponding author on reasonable request.

\section{Ethics approval and consent to participate}

This study was conducted anonymously including children ages 5-12. We obtained verbal and written informed consents from a parent or guardian on behalf of all participants at the parent-teacher conference, and then sent a questionnaire with a detailed informed consent to them. The study was conducted in accordance with the Declaration of Helsinki, and the protocol was approved by the Ethics Committee of Xi'an Jiaotong University (Project identification code:2016-0985).

\section{Consent for publication}

Not applicable.

\section{Competing interests}

The authors have no competing interests to declare.

\section{Author details}

'Department of Epidemiology and Biostatistics, School of Public Heath, Xi'an Jiaotong University, No.76 West Yanta Road, Xi'an 710061, Shaanxi, China.

${ }^{2}$ Department of Renal Dialysis, The First Affiliated Hospital of Xi'an Jiaotong University, No.277 West Yanta Road, Xi'an 710061, Shaanxi, China. 
${ }^{3}$ Department of Nephrology, The Affiliated Children Hospital of Xi'an Jiaotong University, No.69 Xijuyuan Lane, Xi'an 710002, Shaanxi, China. ${ }^{4}$ Department of Breast Cancer, Shaanxi Tumor Hospital, No.309 West Yanta Road, Xi'an 710061, Shaanxi, China. ${ }^{5}$ Department of Dermatology, The Affiliated Children Hospital of Xi'an Jiaotong University, No.69 Xijuyuan Lane, Xi'an 710002, Shaanxi, China. ${ }^{6}$ Department of Pediatric intensive care unit, The Affiliated Children Hospital of Xi'an Jiaotong University, No.69 Xijuyuan Lane, Xi'an 710002, Shaanxi, China. ${ }^{7}$ Shaanxi Institute of Pediatric Diseases, The Affiliated Children Hospital of Xi'an Jiaotong University, No.69 Xijuyuan Lane, Xi'an 710002, Shaanxi, China.

Received: 5 March 2020 Accepted: 12 June 2020

Published online: 22 June 2020

\section{References}

1. Austin PF, Bauer SB, Bower W, Chase J, Franco I, Hoebeke P, et al. The standardization of terminology of lower urinary tract function in children and adolescents: update report from the standardization Committee of the International Children's continence society. Neurourol Urodyn. 2016;35(4): 471-81.

2. Hamed A, Yousf F, Hussein MM. Prevalence of nocturnal enuresis and related risk factors in school-age children in Egypt: an epidemiological study. World J Urol. 2017;35(3):459-65.

3. Sarici H, Telli O, Ozgur BC, Demirbas A, Ozgur S, Karagoz MA. Prevalence of nocturnal enuresis and its influence on quality of life in school-aged children. J Pediatr Urol. 2016; 12(3): 159.e1-6.

4. Bakhtiar K, Pournia Y, Ebrahimzadeh F, Farhadi A, Shafizadeh F, Hosseinabadi R. Prevalence of nocturnal enuresis and its associated factors in primary school and preschool children of Khorramabad in 2013. Int J Pediatr. 2014; 2014:120686.

5. Yazici CM, Nalbantoglu B, Topcu B, Dogan C. Prevalence of nocturnal enuresis and associated factors in schoolchildren in Western Turkey. Can J Urol. 2012;19(4):6383-8.

6. Dolgun G, Savaser S, Balci S, Yazici S. Prevalence of nocturnal enuresis and related factors in children aged 5-13 in Istanbul. Iran J Pediatr. 2012;22(2):205-12

7. Hashem M, Morteza A, Mohammad K, Ahmad-Ali N. Prevalence of nocturnal enuresis in school aged children: the role of personal and parents related socio-economic and educational factors. Iran J Pediatr. 2013;23(1):59-64.

8. Ramírez-Backhaus M, Martínez Agulló E, Arlandis Guzmán S, Gómez Pérez L, Delgado Oliva F, Martínez García R, et al. Prevalence of nocturnal enuresis in the Valencian community. Pediatric section of the National Incontinence Survey. The EPICC study. Actas Urol Esp. 2009;33(9):1011-8.

9. Wang XZ, Wen YB, Shang XP, Wang YH, Li YW, Li TF, et al. The influence of delay elimination communication on the prevalence of primary nocturnal enuresis-a survey from mainland China. Neurourol Urodyn. 2019;38(5):1423-9.

10. Lin GM, Li ZR, Pan XF, Li XL, Fu SM, Liu YL. Analysis on prevalence and characteristics of enuresis among children aged 6-13 years in Zhongshan city. China medical herald. 2017:14(03):109-12 (in Chinese).

11. Wang QW, Wen JG, Song DK, Su J, Zhu QH, Liu K, et al. Bed-wetting in Chinese children: epidemiology and predictive factors. Neurourol Urodyn. 2007;26(4):512-7.

12. Jurković M, Tomašković I, Tomašković M, Smital Zore B, Pavić I, Roić AC Refugee status as a possible risk factor for childhood enuresis. Int J Environ Res Public Health. 2019:16(7):1293.

13. Joinson C, Sullivan S, von Gontard A, Heron J. Stressful events in early childhood and developmental trajectories of bedwetting at school age. J Pediatr Psychol. 2016;41(9):1002-10.

14. Choby BA, George S. Toilet training. Am Fam Physician. 2008;78(9):1059-64.

15. Wang JJ, Wang XZ, Wang YH, Song P, Han ZJ, Hao YT, et al. Effect of urinary training on urination control of infants using nappies after birth. Chin J Appl Clin Pediatr. 2018;33(17):1332-5 (in Chinese)

16. Song P, Huang C, Wang Y, Wang Q, Zhu W, Yue Y, et al. Comparison of desmopressin, alarm, desmopressin plus alarm, and desmopressin plus anticholinergic agents in the management of paediatric monosymptomatic nocturnal enuresis: a network meta-analysis. BJU Int. 2019;123(3):388-400.

17. Wang M, Zhang A, Qin Z, Xu S, Ban S, Zhang J, Ma J, Du X. Abnormal neura responses to emotional stimuli in children with primary monosymptomatic nocturnal enuresis. Eur Child Adolesc Psychiatry. 2019;28(7):949-56.

18. Shah S, Jafri RZ, Mobin K, Mirza R, Nanji K, Jahangir F, et al. Frequency and features of nocturnal enuresis in Pakistani children aged 5 to 16 years based on ICCS criteria: a multi-center cross-sectional study from Karachi. Pakistan BMC Fam Pract. 2018;19(1):198

19. Ma J, Li SH, Jiang F, Zhang YW, Li F, Jin XM. A questionnaire-based epidemiological investigation on the life quality of primary school children with enuresis. Chinese journal of evidence-based pediatrics. 2013;8(03):1725 (in Chinese).

20. Tang HM. Epidemiological investigation on nocturnal enuresis and its related factors in school children in Chengdu. Dissertation: Chongqing Medical University; 2018. (in Chinese).

21. Skevington SM, Lotfy M, O'Connell KA. The World Health Organization's WHOQOL-BREF quality of life assessment: psychometric properties and results of the international field trial. A report from the WHOQOL group. Qual Life Res. 2004;13(2):299-310.

22. Yeung CK, Sreedhar B, Sihoe JD, Sit FK, Lau J. Differences in characteristics of nocturnal enuresis between children and adolescents: a critical appraisal from a large epidemiological study. BJU Int. 2006;97(5):1069-73.

23. Griffiths D. Neural control of micturition in humans: a working model. Nat Rev Urol. 2015;12(12):695-705.

24. Butler RJ, Galsworthy MJ, Rijsdijk F, Plomin R. Genetic and gender influences on nocturnal bladder control--a study of 2900 3-year-old twin pairs. Scand J Urol Nephrol. 2001;35(3):177-83.

25. Savaser S, Kizilkaya Beji N, Aslan E, Gozen D. The prevalence of diurnal urinary incontinence and enuresis and quality of life: sample of school. Urol J. 2018:15(4):173-9.

26. Wen JG, Wang QW, Chen Y, Wen JJ, Liu K. An epidemiological study of primary nocturnal enuresis in Chinese children and adolescents. Eur Urol. 2006;49(6):1107-13.

27. Joinson C, Heron J, Von Gontard A, Butler U, Emond A, Golding J. A prospective study of age at initiation of toilet training and subsequent daytime bladder control in school-age children. J Dev Behav Pediatr. 2009; 30(5):385-93.

28. Hodges SJ, Richards KA, Gorbachinsky I, Krane LS. The association of age of toilet training and dysfunctional voiding. Res Rep Urol. 2014;6:127-30.

29. Tsuji S, Takewa R, Ohnuma C, Kimata T, Yamanouchi S, Kaneko K. Nocturnal enuresis and poor sleep quality. Pediatr Int. 2018;60(11):1020-3.

30. Wada H, Kimura M, Tajima T, Shirahama R, Suzuki Y, Suzuki Y, et al. Nocturnal enuresis and sleep disordered breathing in primary school children: potential implications. Pediatr Pulmonol. 2018;53(11):1541-8.

31. Li S, Jin X, Wu S, Jiang F, Yan C, Shen X. The impact of media use on sleep patterns and sleep disorders among school-aged children in China. Sleep. 2007;30(3):361-7.

32. Mejias SG, Ramphul K. Nocturnal enuresis in children from Santo Domingo, Dominican Republic: a questionnaire study of prevalence and risk factors. BMJ Paediatr Open. 2018:2(1):e000311.

33. Warzak WJ. Psychosocial implications of nocturnal enuresis. Clin Pediatr (Phila). 1993; Spec No:38-40.

34. von Gontard A. Psychological and psychiatric aspects of nocturnal enuresis and functional urinary incontinence. Urologe A. 2004:43(7):787-94.

\section{Publisher's Note}

Springer Nature remains neutral with regard to jurisdictional claims in published maps and institutional affiliations.

Ready to submit your research? Choose BMC and benefit from:

- fast, convenient online submission

- thorough peer review by experienced researchers in your field

- rapid publication on acceptance

- support for research data, including large and complex data types

- gold Open Access which fosters wider collaboration and increased citations

- maximum visibility for your research: over $100 \mathrm{M}$ website views per year

At BMC, research is always in progress.

Learn more biomedcentral.com/submission 